赵文玥,吉喜斌,金博文,焦丹丹,张靖琳, 郭飞,赵丽雯.西北干旱区泡泡刺灌丛的降雨再分配特征及影响因素分析.生态学报, 2022,42( 2)： 804-817.

Zhao W Y, Ji X B, Jin B W, Jiao D D, Zhang J L, Guo F, Zhao L W. Rainfall partitioning patterns of the desert shrub Nitraria sphaerocarpa and its influencing factors in drylands of northwest China. Acta Ecologica Sinica, 2022,42(2) :804-817.

\title{
西北干旱区泡泡刺灌丛的降雨再分配特征及影响因素 分析
}

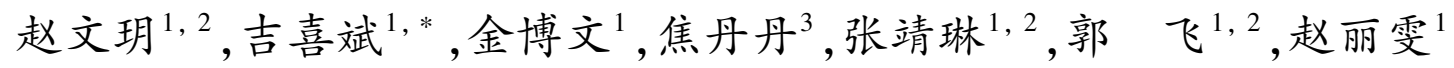 \\ 1 中国科学院西北生态环境资源研究院临泽内陆河研究站, 中国科学院生态水文与流域科学重点实验室, 兰州 730000 \\ 2 中国科学院大学, 北京 100049 \\ 3 北京师范大学地理科学学部, 地表过程与资源生态国家重点实验室, 北京 100875
}

摘要:定量分析植被冠层对降雨再分配过程的影响,是认识陆地生态系统水文循环的重要环节。然而, 由于干旱区天然植被分 布稀疏、形态结构特殊,其降雨再分配过程的测算较为困难,相关研究较少,特别是关于荒漠低矮灌丛的降雨再分配研究鲜有报 道。本文以河西走廊中段临泽绿洲一荒漠过渡带的天然建群种泡泡刺灌丛( Nitraria sphaerocarpa) 为研究对象, 基于 3 年逐个单 次降雨事件的观测数据分析了生长季泡泡刺灌丛的降雨再分配特征及主要影响因素,量化了泡泡刺灌丛覆盖下实际进人土壤 的有效降雨量及其空间分布特征。结果表明: (1) 生长季泡泡刺灌丛的平均穿透率、楖干茎流率和冠层截留损失率分别为 $87.89 \%$ 、1.61\% 和 $10.50 \%$; (2) 降雨量是影响泡泡刺灌丛降雨再分配特征的关键气象因素,其与穿透雨量、树干茎流量、冠层截 留损失量之间具有显著的统计关系 $(P<0.001)$; (3) 与干旱区其他稀疏植被相比,泡泡刺灌丛的穿透率和集流率较高, 冠层截留 损失率较低, 与其特殊的植被形态特征有关, 相关分析的结果表明,泡泡刺灌丛的穿透雨量与植被面积指数和株高呈显著的负 相关关系 $(P<0.001)$, 树干茎流量与树干倾角呈显著的正相关关系 $(P<0.01)$ 。这些研究结果增进了我们对于绿洲一荒漠过渡 带植被对局地水文过程影响的认识, 为合理估算干旱区稀疏植被覆盖下的冠层截留损失提供了方法参考。

关键词:冠层截留损失;穿透雨;树干茎流;有效降雨量;稀疏植被

\section{Rainfall partitioning patterns of the desert shrub Nitraria sphaerocarpa and its influencing factors in drylands of northwest China}

\footnotetext{
ZHAO Wenyue $^{1,2}$, JI Xibin ${ }^{1, *}$, JIN Bowen ${ }^{1}$, JIAO Dandan ${ }^{3}$, ZHANG Jinglin ${ }^{1,2}$, GUO Fei ${ }^{1,2}$, ZHAO Liwen ${ }^{1}$

1 Linze Inland River Basin Research Station, Northwest Institute of Eco-Environment and Resources, Chinese Academy of Sciences; Key Laboratory of Ecohydrology and Watershed Science Chinese Academy of Sciences, Lanzhou 730000, China

2 University of Chinese Academy of Sciences, Beijing 100049, China

3 State Key Laboratory of Earth Surface Processes and Resource Ecology, Faculty of Geographical Science, Beijing Normal University, Beijing 100875, China
}

\begin{abstract}
Analyzing quantitatively the effect of vegetation canopy on rainfall partitioning is an important part for better understanding the hydrological cycle in terrestrial ecosystems, which is particularly useful for hydrologic budget estimation, hydrological models' establishment and afforestation projects' implement in drylands. However, it is difficult to measure and calculate its rainfall partitioning process of the natural vegetation in the drylands due to its sparse distribution and special morphological structure, and very few field measurements have conducted specially for the natural desert dwarf shrub species, which distributed widely in the oasis-desert ectone of northwestern China. Here we present results of the
\end{abstract}

基金项目: 国家自然科学基金项目 (41771041,41630861)

收稿日期:2021-01-22; 网络出版日期:2021-09-10

* 通讯作者 Corresponding author.E-mail: xuanzhij@ lzb.ac.cn， 
partitioning of rainfall into throughfall $(T F)$, stemflow $(S F)$ and interception loss $(I L)$ by a shrub species Nitraria sphaerocarpa, a naturally dominant species of Linze oasis-desert ecotone in the middle part of the Hexi Corridor, based on the observation data during the growing season for 3 years. Consequently, the effective rainfall that actually enters the soil and its spatial distribution characteristics beneath the $N$. sphaerocarpa canopy are quantified. We also analyze the influencing factors for rainfall partitioning by N. sphaerocarpa canopy. The results show that: (1) on average, the measured throughfall, stemflow and derived interception loss by N. sphaerocarpa during growing season account for $87.89 \%, 1.61 \%$ and $10.50 \%$ of gross rainfall amount, respectively. The average funneling ratio for $N$. sphaerocarpa is $(129.66 \pm 93.01)$ and its canopy storage capacity is $0.42 \mathrm{~mm}$. N. sphaerocarpa's throughfall is produced from rainfall events with total amount more than $0.2 \mathrm{~mm}$, while its stemflow does not occur following rainfall events less than $1.5 \mathrm{~mm}$. (2) Rainfall amount is the key meteorological factor affecting the rainfall partitioning characteristics. There are significant correlations between rainfall amount and throughfall, stemflow and interception loss $(P<0.001)$. Other meteorological variables like canopy surface temperature, atmospheric temperature, atmospheric humidity and vapor pressure can also affect rainfall redistribution process. (3) Compared with other sparse vegetation in drylands, the N. sphaerocarpa has higher throughfall percentage and funneling ratio, but lower interception loss percentage. Special canopy morphology of $N$. sphaerocarpa may play an important role in its pattern of rainfall partitioning. Pearson correlation analysis shows that throughfall has significantly negative correlation with plant area index $(\mathrm{PAI})$ and shrub height $(P<0.001)$, and stemflow has positive correlation with stem orientation $(P<0.01)$. Other canopy morphology like bark roughness, leaf shape and canopy form, which lack of quantitative description, are also vital for rainfall partitioning patterns. The results might improve better understanding of shrubs' role on the local hydrological processes in oasis-desert ecotone, and provide a reasonable method for estimating interception loss by sparse vegetation in drylands.

Key Words : interception loss; throughfall; stemflow; effective rainfall ; sparse vegetation

冠层降雨再分配是指降雨进人植被冠层后被重新分配为冠层截留损失、穿透雨和树干茎流的过程 ${ }^{[1-2]}$ 。 其中冠层截留损失是指被冠层拦截、储存, 在降雨过程中或降雨结束后以蒸发形式返回大气的雨水 ${ }^{[3-4]}$, 是地 表蒸散发的重要组分 ${ }^{[5]}$, 也是冠层降雨再分配过程中水分的净损失项 ${ }^{[6]}$ 。穿透雨是指透过冠层到达地面的 降雨, 包括从冠层缝隙直接滴落地面的自由穿透雨和从冠层枝叶滴落地面的释放穿透雨 ${ }^{[7]}$, 穿透雨约占大气 降雨的 50\%- $80 \%{ }^{[8-10]}$, 是冠层下表层土壤水分的主要来源 ${ }^{[1-12]}$ 。树干茎流是指沿树枝、树干向树根流动, 最终以点源的形式到达深层土壤中的雨水 ${ }^{[13-14]}$, 虽数量较少, 但集流率 ${ }^{[15]}$ 和富集率 ${ }^{[16]}$ 极高, 是冠层下 “湿 岛” ${ }^{[13,17]}$ 和 “沃岛” ${ }^{[13,18]}$ 效应形成发展的重要促进因子。穿透雨和树干茎流合称净降雨量, 是最终到达土壤 可供冠层下植被利用的有效降雨量 ${ }^{[1,19]}$ 。因此,冠层降雨再分配对局地水文过程和水文功能具有重要影响, 是局地水文循环中不可忽视的重要环节 ${ }^{[20]}$ 。

在干旱区生态系统中, 受水分和养分资源的限制, 植被在空间上通常呈现斑块或条带状稀疏分布 ${ }^{[21-22]}$ 。 降雨是该地区天然生态系统的主要补给水源, 其数量稀少、时空分布不均且变率较大, 以小降雨事件为 主 $^{[2,23]}$ 。稀疏植被冠层对于降雨的再分配作用改变了降雨特性及其时空分配格局 ${ }^{[20]}$, 对冠层下土壤水分、养 分的时空分布 ${ }^{[12-13,24]}$ 、生物群落的演替与分布 ${ }^{[25]}$ 、地下水的补给 ${ }^{[26]}$ 、区域降雨循环 ${ }^{[27]}$ 等一系列生态水文过 程产生影响。多年来,关于干旱区稀疏植被冠层降雨再分配的研究取得了重要进展,主要集中于不同种类稀 疏植被冠层降雨再分配的比例构成 ${ }^{[28-29]}$ 、变化趋势 ${ }^{[30]}$ 、影响因素分析 ${ }^{[4,29,31]}$ 及模型构建 ${ }^{[32-34]}$ 等。但由于干 旱区植被形态结构特殊 ${ }^{[14]}$ 、分布稀疏 ${ }^{[2]}$ 且具有显著的空间异质性 ${ }^{[35]}$, 其降雨再分配过程的观测实验较为困 难,相关长时间尺度的研究较少; 在构建稀疏植被冠层截留模型时,一般基于水量平衡的原理估算冠层截留损 失, 假设其数值上等于林外降雨量与净降雨量之差 ${ }^{[7]}$, 但多数忽略了树干茎流分量的测算; 在探讨植被形态 结构因子对冠层降雨再分配过程的影响时, 多基于叶面积指数, 但对干旱区稀疏植被的观测表明叶片的持水 能力低于枝条和树干, 所以枝条和树干在冠层降雨再分配的过程中发挥重要作用 ${ }^{[11,36]}$, 因此在构建干旱区稀 
疏植被冠层截留模型及探讨相关影响因素时,应对此特征加以考虑, 仅使用叶面积可能不能真实准确地反映 植被冠层对降雨再分配过程的调节作用。

泡泡刺 (Nitraria sphaerocarpa) 为西北干旱区特有的古老荒漠残遗种, 属超旱生灌木, 是西北干旱区河西 走廊中段绿洲一荒漠过渡带的天然建群种植物, 通常以灌丛沙堆的形式存在 ${ }^{[37]}$, 在防风固沙、稳定绿洲环境 等方面具有重要生态意义 ${ }^{[38-39]}$ 。本文以泡泡刺灌丛为研究对象,通过 2016 年、2017 年和 2020 年生长季对泡 泡刺灌丛的冠层降雨再分配过程、植被形态特征、林外降雨特征、气象因素进行野外定位观测,分析了泡泡刺 灌丛冠层降雨再分配的比例构成及主要影响因素 (包括降雨特征、植被形态结构特征和气象因素),构建了冠 层降雨再分配要素随降雨特征变化的经验回归方程,揭示了泡泡刺冠层下穿透雨的空间分布规律及树干茎流 的聚集效应。以期增进对于干旱区稀疏植被覆盖下冠层降雨再分配过程及其影响机理的定量认识, 为干旱区 类似植被分布区水文循环过程中冠层截留损失分量的测算和水分收支评估提供可以借鉴的方法, 以促进绿 洲一荒漠过渡带的植被恢复和生态建设实践。

\section{1 材料与方法}

\section{1 研究区概况}

野外观测实验地位于中国科学院临泽内陆河研究站 $\left(39^{\circ} 20^{\prime} 50^{\prime \prime} \mathrm{N}, 100^{\circ} 07^{\prime} 48^{\prime \prime} \mathrm{E}\right)$ 绿洲-荒漠过渡带生态水 文过程试验区, 地处河西走廊中段, 北邻巴丹吉林沙漠, 南邻黑河中游临泽绿洲, 海拔 $1384 \mathrm{~m}$ 。该地区属典型 的温带大陆性气候, 夏季高温少雨, 冬季寒冷干燥, 年平均气温 $9.2^{\circ} \mathrm{C}$, 多年平均降雨量为 $124 \mathrm{~mm}$, 主要集中在 6-9 月, 降雨变率大, 以小降雨事件为主, 年均蒸发量 $2390 \mathrm{~mm}{ }^{[40-41]}$ 。

研究区的植被群落大多呈现斑块状稀疏分布, 植被结构简单, 主要建群灌木有梭梭 (Haloxylon ammodendron)、泡泡刺 (N. sphaerocarpa)、沙拐苯 (Calligonum mongolicum), 同时零散分布着花棒 (Hedysarum scoparium)、多枝怪柳 (Tamarix ramosissima) 等, 在降雨较多的年份雾冰藜 (Bassia dasyphylla)、白茎盐生草 (Halogeton arachnoideus)、小画眉草( Eragrostis minor Host) 等一年生草本发育。泡泡刺灌丛约占研究区总植 被盖度的 $45 \%$, 是该地区典型的天然稀疏植被 ${ }^{[40]}$ 。

\section{2 植被的选择及相关植被要素的测量}

首先, 对研究区泡泡刺灌丛的分布位置、基径、株高等展开植被调查 ${ }^{[40]}$; 随后, 在研究区随机选择 1 堆典 型的、长势良好的泡泡刺灌丛作为研究对象, 并测定了影响其冠层降雨再分配过程的冠层结构参数,包括株 高、冠层投影面积、树干倾角 (指枝条与水平方向的夹角)、植被面积指数 (Plant area index, PAI) 等(具体植被 特征见表 1)。其中株高、冠层厚度、基径、树干倾角在 2016 年 8 月、2017 年 7 月、2020 年 6 月观测实验开始前 测定。冠层投影面积在 2020 年 8 月利用无人机拍摄照片, 随后运用 Photoshop 2020 软件处理, 再通过 MATLAB R2018b 计算得到。植被面积指数是指单位土地面积上冠层总表面积的一半 ${ }^{[42]}$, 由叶面积指数、枝 面积指数和茎面积指数等共同组成 ${ }^{[43]}$, 是对植被结构和覆盖状况的整体描述 ${ }^{[44-45]}$ 。研究区泡泡刺灌丛的叶 面积仅占其冠层表面积的一部分, 枝、茎等对雨水的截留再分配作用同样不可忽视。因此,采用 PAI 能更好 地反映泡泡刺冠层对降雨再分配过程的调节作用。PAI 数据由 2016 年、2017 年、2020 年 8 月运用 LAI- 2200C 植物冠层分析仪 (LI-COR Inc, Lincoln，Nebraska，USA) 在冠层下集雨瓶所在位置贴近地表逐个测定而来。

表 1 泡泡刺灌丛冠层形态结构特征的基本信息

Table 1 The basic information of Nitraria sphaerocarpa's morphological structures

\begin{tabular}{lcccccc}
\hline 植被类型 & $\begin{array}{c}\text { 冠层投影面积 } \\
\text { Spanopy } \\
\text { projected } \\
\text { area } / \mathrm{m}^{2}\end{array}$ & $\begin{array}{c}\text { 株高 } \\
\text { Shrub } \\
\text { height } / \mathrm{cm}\end{array}$ & $\begin{array}{c}\text { 冠层厚度 } \\
\text { Canopy } \\
\text { thickness } / \mathrm{cm}\end{array}$ & $\begin{array}{c}\text { PAI } \\
\text { Plant area } \\
\text { index/ } \\
\left(\mathrm{m}^{2} / \mathrm{m}^{2}\right)\end{array}$ & $\begin{array}{c}\text { 基径 } \\
\text { Stem } \\
\text { diameter } / \mathrm{cm}\end{array}$ & $\begin{array}{c}\text { 树干倾角 } \\
\text { Stem } \\
\text { orientation } /\left({ }^{\circ}\right)\end{array}$ \\
\hline 泡泡刺 Nitraria sphaerocarpa & 22.37 & $48.45 \pm 9.00$ & $43.91 \pm 9.51$ & $1.87 \pm 0.36$ & $0.48 \pm 0.089$ & $68.55 \pm 18.48$ \\
\hline
\end{tabular}

数据为平均值 \pm 标准差 


\section{3 林外降雨特征及其他气象要素的测定}

林外降雨特征由布设在泡泡刺灌丛周边开阔地带的翻斗式雨量筒( TE525MM, Texas Electronics Inc., Dallas, TX) 测定, 通过数据采集器 (CR1000-XT, Campbell Scientific, UT, USA) 自动记录数据, 每 30 min 计算 平均值并储存,精度 $0.1 \mathrm{~mm}$ 。同时分别在泡泡刺灌丛 $0^{\circ} 、 120^{\circ} 、 240^{\circ}$ 方向的空地布设 3 个雨量筒, 用于雨量订 正。雨水的收集以次降雨事件为基础,若降雨间隔小于 $6 \mathrm{~h}$, 则视为一次降雨事件。降雨结束后立刻进行雨量 的测定, 若降雨发生在夜间, 则第二天清晨进行收集, 以减小截留雨水蒸发对观测造成的影响。其他气象要素 包括风速、风向、温度、湿度、净辐射等由林外空地的自动气象站实时监测 ${ }^{[40]}$ 。

\section{4 穿透雨的测量及计算}

穿透雨通过自制的集雨瓶收集,集雨瓶由内径 $6 \mathrm{~cm}$ 、高 $13.5 \mathrm{~cm}$ 的玻璃杯上部叠加内径 $11 \mathrm{~cm}$ 、外缘高 $2 \mathrm{~cm}$ 的聚乙烯漏斗组成 (图 1)。将集雨瓶以灌丛中心为圆心, 呈辐射状均匀放置于北、东北、东、东南、南、西 南、西、西北 8 个方向的半径上,相邻两个集雨瓶间隔 $20 \mathrm{~cm}$,共布设 93 个集雨瓶(图 1)。由于泡泡刺灌丛的 枝条大多呈现匍匐状贴近沙丘表面, 故将集雨瓶部分埋人土壤, 顶部露出地表 5-8 cm, 以避免集雨瓶碰触枝 条, 同时减小风对集雨瓶摆放位置的影响。穿透雨量的计算方法如下:

$$
T F=\frac{\sum_{i=1}^{m}(V T)_{i} \times 10}{m \times F A}
$$

式中, $T F$ 是穿透雨量 $(\mathrm{mm}) ; V T$ 为第 $i$ 个集雨瓶中穿透雨的体积 $(\mathrm{mL}) ; m$ 是冠层下集雨瓶的数量; $F A$ 为漏斗 的横截面积 $\left(\mathrm{cm}^{2}\right)$ 。

\section{5 树干茎流的测量及计算}

在灌丛 8 个方位上各选择 2 株,共 16 株泡泡刺作为标准枝收集树干茎流。具体步骤如下: 首先,将小漏 斗 (内径 $3.2 \mathrm{~cm}$ ) 侧面钻孔剖开, 固定在树干接近地表处; 然后, 为防止穿透雨的浌人, 在漏斗敞口处覆盖钻孔 后的铝䈃纸, 铝䈃纸上圆孔的直径稍大于树干直径 4-5 $\mathrm{mm}$ 确保树干茎流可以流人; 最后, 用导水管连接漏 斗排水口和收集瓶, 并用硅胶密封接缝处 (图 1)。借鉴标准枝法 ${ }^{[46]}$ 推算整个灌丛产生的树干茎流体积, 即用 标准枝的平均树干茎流体积乘整个灌丛的枝条数。树干茎流量的计算公式如下:

$$
S F=\frac{V S}{S_{P} \times 1000}
$$

式中, $S F$ 为树干茎流量 $(\mathrm{mm}) ; V S$ 为整个泡泡刺灌丛的树干茎流体积 $(\mathrm{mL}) ; S_{P}$ 为整个泡泡刺灌丛的冠层投影 面积 $\left(\mathrm{m}^{2}\right)$ 。此外, Herwitz 等 ${ }^{[15]}$ 提出集流率的概念, 用于定量分析树干茎流对水分的聚集作用, 具体公式 如下:

$$
F R=\frac{V S \times 10}{B A \times P g}
$$

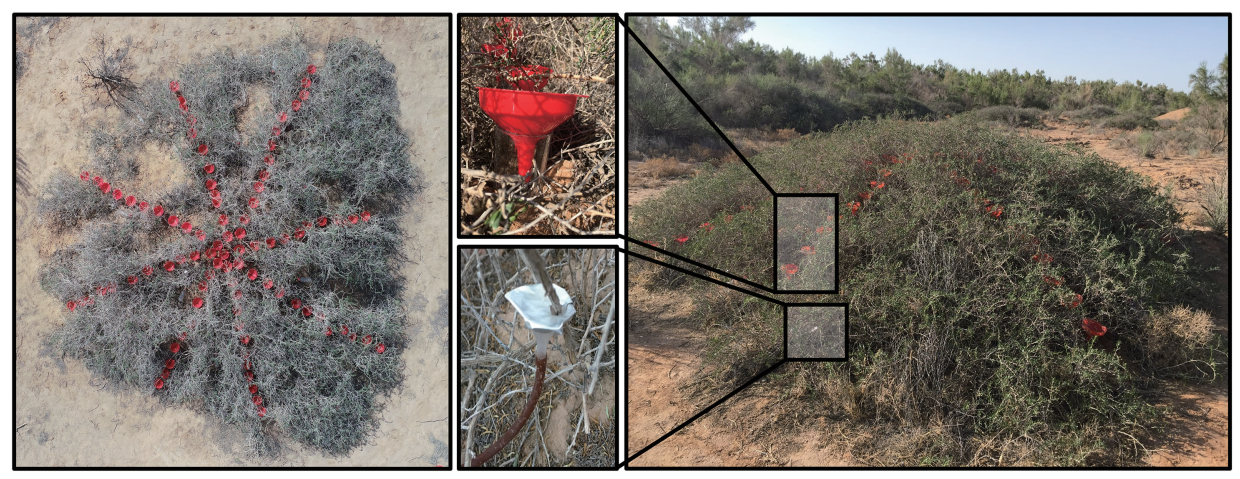

图 1 泡泡刺灌丛穿透雨和树干茎流收集装置示意图

Fig.1 The device for collecting rainfall redistribution in field, with details of homemade stemflow collectors and throughfall gauges 
式中, $F R$ 为集流率; $V S$ 为树干茎流的体积 $(\mathrm{mL}) ; B A$ 为树干基部的横截面积 $\left(\mathrm{cm}^{2}\right) ; P g$ 为林外降雨量 $(\mathrm{mm})$ 。 集流率即表示流经单位树干横截面积上的树干茎流量与林外降雨量的比值。集流率大于 1 , 表示除了树干之 外, 冠层的其他组分对树干茎流的产生和聚集具有促进作用 ${ }^{[15,17]}$ 。

1.6 冠层截留损失的计算

由于冠层截留损失难以直接测量, 通常根据水量平衡的原理进行估算, 其数值上等于总降雨量与净降雨 量之差:

$$
I L=P g-N=P g-(T F+S F)
$$

式中, $I L$ 为冠层截留损失量 $(\mathrm{mm}) ; P g$ 为林外降雨量 $(\mathrm{mm}) ; N$ 为净降雨量 $(\mathrm{mm}) ; T F$ 为穿透雨量 $(\mathrm{mm}) ; S F$ 为 树干茎流量 $(\mathrm{mm})$ 。

\section{7 数据处理}

利用 SPSS 22 进行描述性统计和 Pearson 相关分析,Pearson 相关分析的显著性检验采用“双尾检验”;使 用 Origin 2018 进行回归分析、曲线拟合及制图, 回归分析和曲线拟合后,采用单因素方差分析对回归系数进 行显著性检验，显著水平设定为 $\alpha=0.05$; 运用 ArcGIS 10.2 对穿透率和 PAI 进行克里金插值并绘制其空间分 布图。

\section{2 结果与分析}

2.1 试验期间研究区的降雨特征

试验期间 (2016 年 8 月、2017 年 7 月、2020 年 6-9 月)共观测到可产生穿透雨的有效降雨事件 23 次, 总 降雨量为 $90.9 \mathrm{~mm}$, 单次平均降雨量为 $(4.0 \pm 4.5) \mathrm{mm}$, 最小值为 $0.2 \mathrm{~mm}$, 最大值为 $17.9 \mathrm{~mm}$ 。将降雨量分为 $<2$ $\mathrm{mm} 、 2-5 \mathrm{~mm} 、 5-10 \mathrm{~mm} 、 10-20 \mathrm{~mm} 4$ 个雨量级, 频数分别为 $12 、 5 、 4 、 2$, 累积降雨量分别为 $12.3 \mathrm{~mm} 、 17.5$ $\mathrm{mm} 、 31.0 \mathrm{~mm} 、 30.1 \mathrm{~mm}$ (图 2)。其中 $<2 \mathrm{~mm}$ 的降雨事件发生次数最多, 但其累积降雨量最小, 对总降雨量的影 响小。> $>5 \mathrm{~mm}$ 的降雨事件仅发生 6 次,但其累积降雨量占总雨量的比例高达 $67.2 \%$, 对总降雨量的贡献较大。 实验期间降雨强度的波动较小, 平均雨强为 $(0.8 \pm 0.5) \mathrm{mm} / \mathrm{h}$, 最小值为 $0.2 \mathrm{~mm} / \mathrm{h}$, 最大值为 $2.6 \mathrm{~mm} / \mathrm{h} 。$ 雨强 $<0.5 \mathrm{~mm} / \mathrm{h}$ 的降雨事件发生次数最多, 共发生 9 次, 但其累积降雨量仅占总降雨量的 $9.7 \%$ 。雨强介于 $0.5-$ $1.5 \mathrm{~mm} / \mathrm{h}$ 范围内的降雨事件对总降雨量的贡献最大。雨强 $>1.5 \mathrm{~mm} / \mathrm{h}$ 的降雨事件发生频次最少, 对总降雨量 的贡献也相对较小。实验期间总降雨历时为 $97 \mathrm{~h}$, 平均降雨历时为 $(4.2 \pm 3.7) \mathrm{h}$ 。历时 $<2 \mathrm{~h}$ 的降雨事件发生 频率最高, 共发生 11 次,但其累积降雨量最小,约占总降雨量的 $15.6 \%$ 。历时 $>10 \mathrm{~h}$ 的降雨事件很少发生, 仅 发生 2 次, 但其累积降雨量占总降雨量的比例最大, 约为 $33.1 \%$ 。总体来看, 实验期间研究区以低雨强、短历 时的小降雨事件为主, 但该类降雨事件对总降雨量的贡献较小, 主要降雨量源于发生次数较少的中雨强、长历 时的大降雨事件。

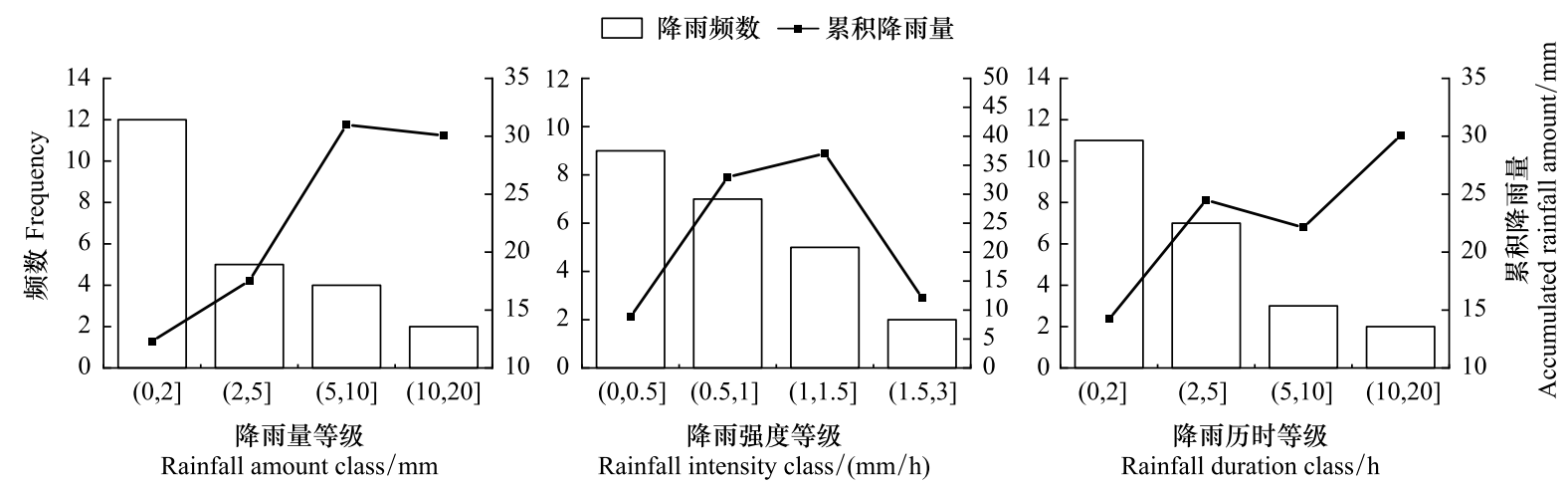

图 2 实验期间降雨量、降雨强度、降雨历时分布特征

Fig.2 Characteristics of rainfall amount, rainfall intensity and rainfall duration distribution during the experiment 
2.2 穿透雨与降雨特征和冠层结构特征的关系

试验期间,泡泡刺灌丛的累计穿透雨量为 $78.89 \mathrm{~mm}$,约占总降雨量的 $87.89 \%$ 。以单次降雨事件来看,泡 泡刺灌丛穿透雨量的变化范围在 0.14-16.68 mm 之间,平均值约为 $(3.47 \pm 4.16) \mathrm{mm}$ 。穿透雨量占次降雨量 的比例 (简称穿透率)介于 $73.00 \%-98.69 \%$, 平均值约为 $(84.95 \pm 7.28) \%$ 。穿透雨的变异系数在 $14.45 \%-$ $77.31 \%$ 之间波动, 平均值约为 $(29.76 \pm 12.61) \%$ 。

降雨特征是影响泡泡刺灌丛穿透雨特征的重要因素,通过回归分析和曲线拟合,建立了泡泡刺灌丛穿透 雨量和穿透率与降雨特征的回归方程 (图 3)。由图 3 所示, 穿透雨量与降雨量、降雨历时之间呈显著线性正 相关关系 $(P<0.0001)$, 与降雨强度之间呈现幂函数关系 $(P<0.01)$ 。表明穿透雨量随降雨量、降雨强度、降雨 历时的增加而增加, 当雨强 $>1.5 \mathrm{~mm} / \mathrm{h}$ 后, 穿透雨量的增加速率加快, 可能是由于高雨强的降雨事件更易造成 雨水的飞溅, 加速截留雨水向释放穿透雨转化导致。根据穿透雨量与降雨量的线性回归方程推算, 泡泡刺灌 丛穿透雨产生的阈值约为 $0.2 \mathrm{~mm}$, 与实测结果 $0.2 \mathrm{~mm}$ 基本一致。穿透率与降雨历时之间呈线性正相关关系 $(P=0.04)$, 与降雨量、降雨强度之间无显著相关性 (图 3)。
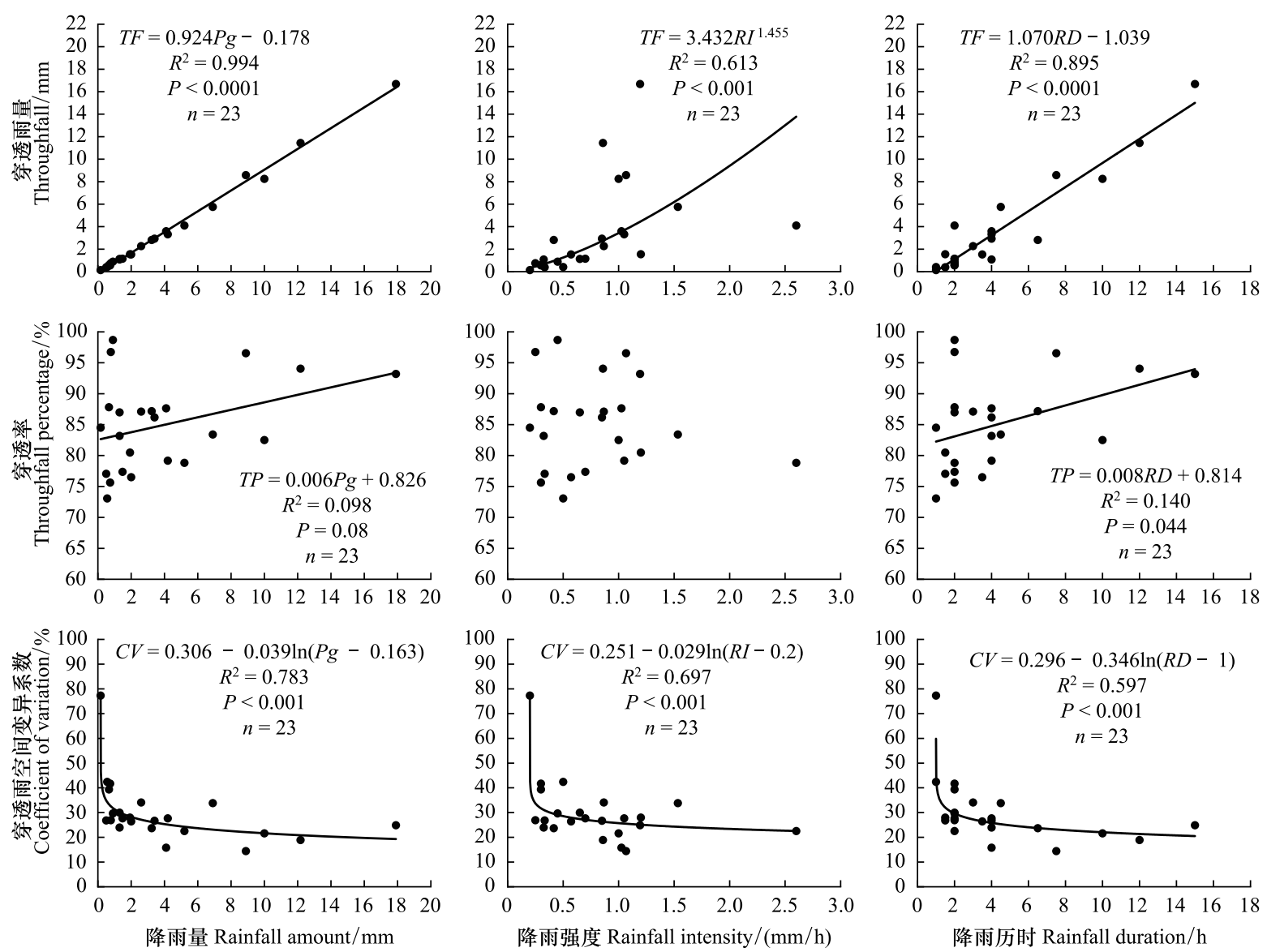

图 3 穿透雨量、穿透率、穿透雨的空间异质性与降雨特征之间的回归关系

Fig.3 The correlation between throughfall, throughfall percentage, coefficient of throughfall spatial variability and rainfall regimes $T F$ : 穿透雨量 Throughfall; $T P$ : 穿透率 Throughfall percentage; $C V$ : 穿透雨空间变异系数 Coefficient of variation; $P g$ : 降雨量 Rainfall amount; $R I$ : 降雨强度 Rainfall intensity; $R D$ : 降雨历时 Rainfall duration; $n$ : 样本数量 Sample number

冠层结构特征通过改变穿透雨的传输路径对冠层下穿透雨的多寡产生不可忽视的影响,相关性分析表 明,平均穿透雨量与株高和 PAI 之间呈现极显著的负相关关系 $(P<0.0001)$, 通过对其进行曲线拟合发现线性 函数的拟合效果最好 $(P<0.0001)$ ( 图 4)。即穿透雨量随株高和 PAI 的增加而下降, 可能是由于当株高和 PAI 较高时,雨水更易被冠层截留,进而减少了穿透雨的形成。 

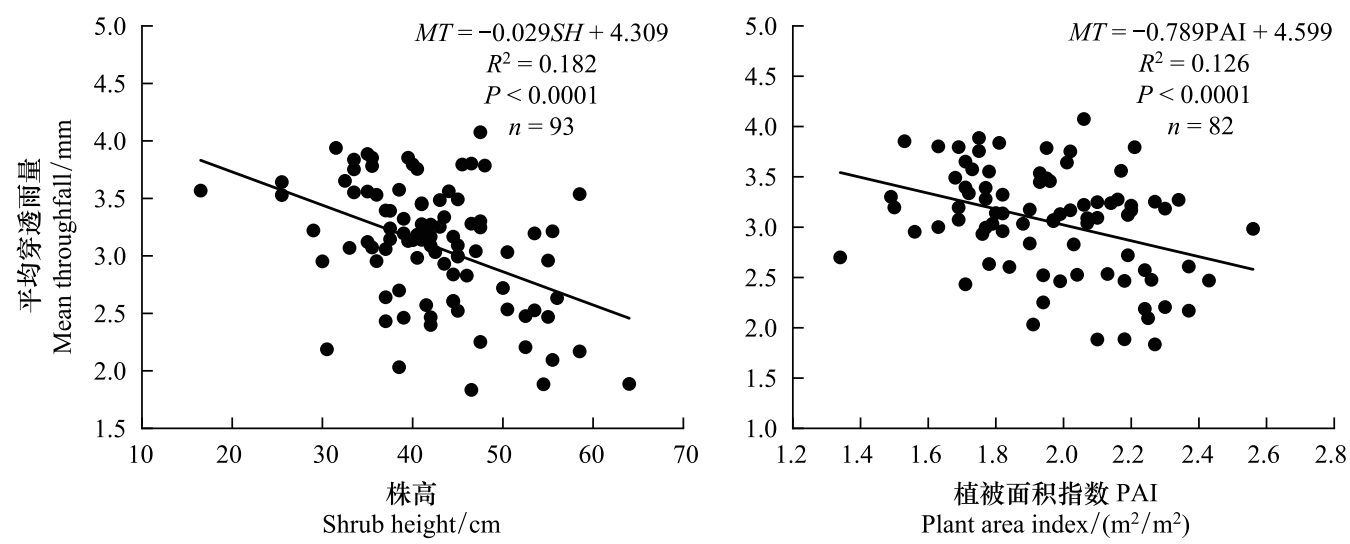

图 4 平均穿透雨量与株高、PAI 之间的回归关系

Fig.4 The correlation between mean throughfall and shrub height, PAI

$M T$ : 单个穿透雨量筒的平均穿透雨量 Mean throughfall; $S H$ : 株高 Shrub height; PAI: 植被面积指数 Plant area index

穿透雨的空间分布具有明显的空间异质性,利用穿透雨的变异系数来反映穿透雨空间分布的异质性,将 其与降雨特征之间进行回归分析, 结果表明,随降雨量、降雨强度、降雨历时的增加,泡泡刺灌丛穿透雨的空间 异质性逐渐减弱, 对数函数的拟合效果较好 $(P<0.01)$ ( 图 3)。为进一步探索穿透雨空间分布的特征,运用克 里金插值绘制了不同雨量级下穿透率的空间分布图。如图 5 所示,随降雨量的增加,穿透雨的空间异质性逐 渐减弱, 高强度的降雨事件也有可能减弱穿透雨的空间异质性,与回归分析的结果一致。此外, 由图 5 可知穿 透率的空间分布呈现多个“雨极” 和“旱区”镶嵌分布的模式, “雨极” 通常出现在灌丛外缘, 而 “旱区”则通常 出现在灌丛中部,推测可能是由于 PAI 的空间异质性导致,因此,运用克里金插值绘制了 PAI 的空间分布图, 发现 PAI 的高值区对应穿透率的“旱区”,而低值区则对应“雨极”。

\section{3 树干茎流与降雨特征和冠层结构的关系}

试验期间共观测到树干茎流 13 次,总树干茎流量为 $1.46 \mathrm{~mm}$,约占总降雨量的 $1.61 \%$ 。从单次降雨事件 来看,泡泡刺灌丛树干茎流量的变化范围在 $0.003-0.41 \mathrm{~mm}$, 平均值约为 $(0.11 \pm 0.11) \mathrm{mm}$ 。树干茎流量占次 降雨量的比例(简称树干茎流率)介于 $0.20 \%-2.41 \%$ 之间,平均值约为 $(1.55 \pm 0.78) \%$ 。

降雨特征是影响树干茎流形成过程的重要因素,通过对泡泡刺灌丛的树干茎流量和树干茎流率与降雨特 征进行回归分析和曲线拟合,其变化趋势见图 6 。树干茎流量与降雨量、降雨历时之间呈显著的线性正相关 关系 $(P<0.001)$, 与降雨强度之间呈指数函数关系 $(P<0.01)$, 表明树干茎流量先随雨强的增加而迅速增加, 当 雨强 $>1 \mathrm{~mm} / \mathrm{h}$ 后, 树干茎流的增加速率逐渐减缓, 可能是由于高雨强的降雨事件更易加剧截留雨水的迸溅, 进而减少截留雨水向树干茎流转化导致。根据树干茎流量与降雨量之间的回归方程推算树干茎流产生的阈 值约为 $1.1 \mathrm{~mm}$, 与实际观测值 $1.5 \mathrm{~mm}$ 近似。树干茎流率随降雨量、降雨强度和降雨历时的增加呈对数函数 的增长趋势 $(P<0.01)$, 当降雨量 $<6 \mathrm{~mm}$ 、降雨强度 $<1.5 \mathrm{~mm} / \mathrm{h}$ 、降雨历时 $<6 \mathrm{~h}$ 时, 树干茎流率随降雨量、降雨强 度和降雨历时的增加而迅速增加,但超过这一范围后,树干茎流率逐渐趋于稳定。推测这一现象可能与泡泡 刺灌丛树干的最大输水能力有关, 当雨量、雨强、降雨历时较大, 超过树干最大输水能力时, 多余的雨水可能以 穿透雨的形式滴落,进而减缓了树干茎流率的增加速率。

冠层结构特征同样在树干茎流形成的过程中发挥不可忽视的作用,单株泡泡刺产生的树干茎流量与冠层 结构特征的相关分析结果见表 2 。泡泡刺的树干茎流量与树干倾角之间呈现显著的正相关关系 $(P=0.005)$, 即树干茎流量随树干倾角的增加而增加,而其与 PAI、基径、株高、冠层厚度和冠层投影面积之间没有显著的 相关性。 


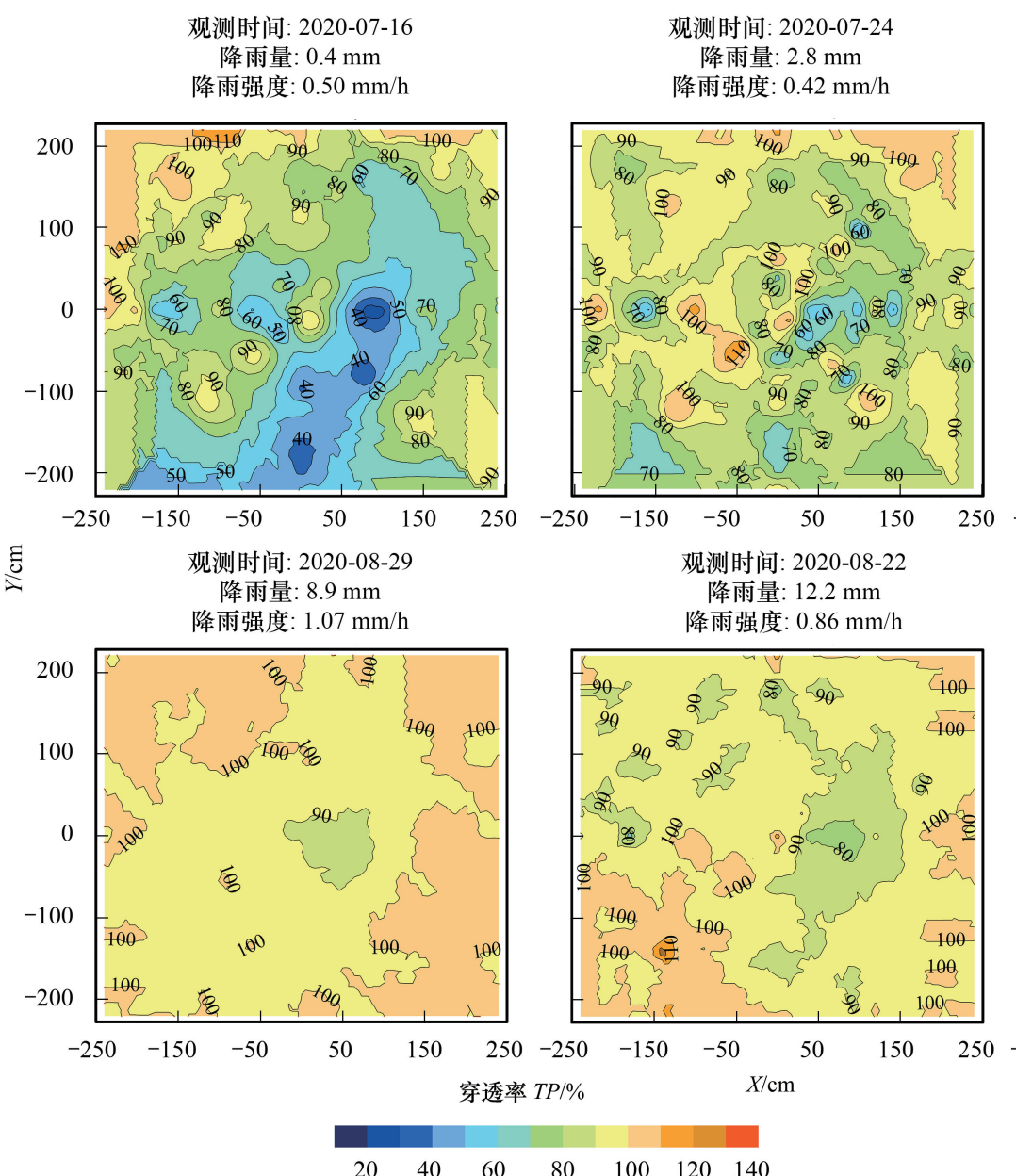

图 5 泡泡刺灌丛穿透率和 PAI 的空间分布图
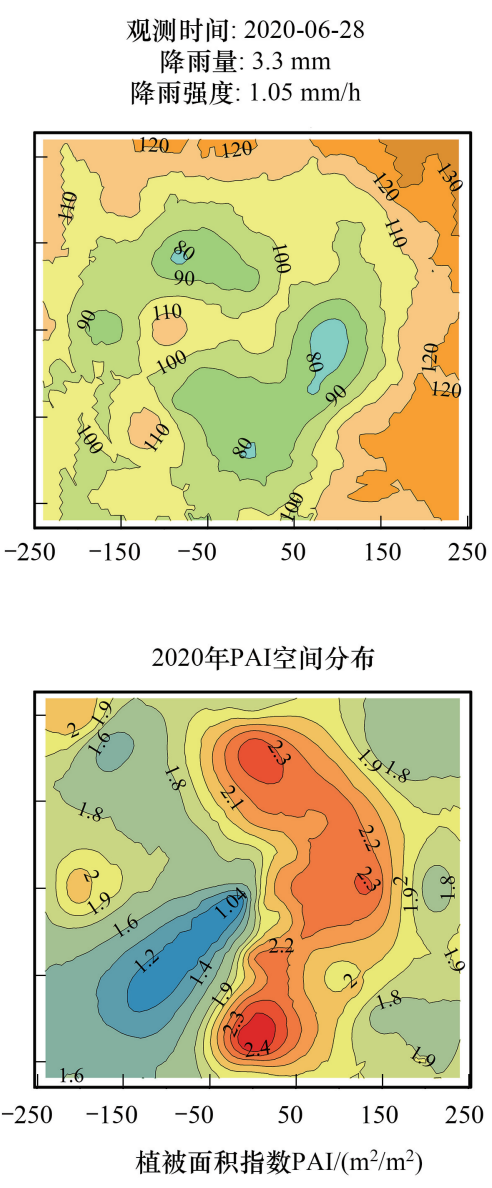

1.21 .41 .61 .81 .92 .02 .12 .22 .32 .42 .5

Fig.5 Spatial distribution of throughfall percentage and PAI for Nitraria sphaerocarpa

$T P$ : 穿透率 Throughfall percentage; PAI: 植被面积指数 Plant area index

表 2 单株泡泡刺的树干茎流量与冠层结构特征的相关分析

Table 2 Correlation analysis of stemflow with canopy morphological characteristics for single Nitraria sphaerocarpa

\begin{tabular}{lcccccc}
\hline & $\begin{array}{c}\text { 树干倾角 } \\
\text { Stem } \\
\text { orientation } /\left({ }^{\circ}\right)\end{array}$ & $\begin{array}{c}\text { PAI } \\
\text { Plant area index/ } \\
\left(\mathrm{m}^{2} / \mathrm{m}^{2}\right)\end{array}$ & $\begin{array}{c}\text { 基径 } \\
\text { Stem } \\
\text { diameter } / \mathrm{cm}\end{array}$ & $\begin{array}{c}\text { 株高 } \\
\text { Shrub } \\
\text { height } / \mathrm{cm}\end{array}$ & $\begin{array}{c}\text { 冠层厚度 } \\
\text { Canopy } \\
\text { thickness } / \mathrm{cm}\end{array}$ & $\begin{array}{c}\text { 冠层投影面积 } \\
\text { Canopy projected } \\
\text { area } / \mathrm{m}^{2}\end{array}$ \\
\hline 树干茎流量 Stemflow $/ \mathrm{mL}$ & $0.78^{* * *}$ & -0.034 & -0.18 & 0.29 & 0.14 & -0.20 \\
\hline
\end{tabular}

$*$ 表示在 0.05 级别 (双尾), 相关性显著; **表示在 0.01 级别 (双尾), 相关性显著

泡泡刺灌丛的集流率在 3.38-306.35 之间波动, 平均值约为 $(129.66 \pm 93.01)$, 表明与空地相比, 泡泡刺灌 丛的树干茎流对雨水具有明显的聚集作用,可将 129.66 倍的雨水输送到根际区。由回归分析可知,集流率与 降雨量、降雨强度、降雨历时之间具有极显著的相关性 $(P<0.001)$, 分别呈现指数、对数和线性函数关系 $(P<$ 0.001 ) (图 6)。当降雨量 $<6 \mathrm{~mm}$, 降雨强度 $<0.8 \mathrm{~mm} / \mathrm{h}$ 时, 集流率随雨量、雨强的增加而迅速增加, 而后增加 速率减缓,该现象可能与泡泡刺灌丛的冠层持水能力和树干输水能力有关。

2.4 冠层截留损失与降雨特征和冠层特征的关系

根据水量平衡余项法推算试验期间共产生冠层截留损失 $9.54 \mathrm{~mm}$,约占总降雨量的 $10.50 \%$ 。从单次降 雨事件来看, 泡泡刺灌丛冠层截留损失量的变化范围在 $0.01-1.53 \mathrm{~mm}$, 平均值约为 $(0.42 \pm 0.39) \mathrm{mm}_{\circ}$ 冠层截 留损失占次降雨量的比例(简称冠层截留损失率)介于 $1.31 \%-26.93 \%$,平均值约为 $(14.21 \pm 7.52) \%$ 。 

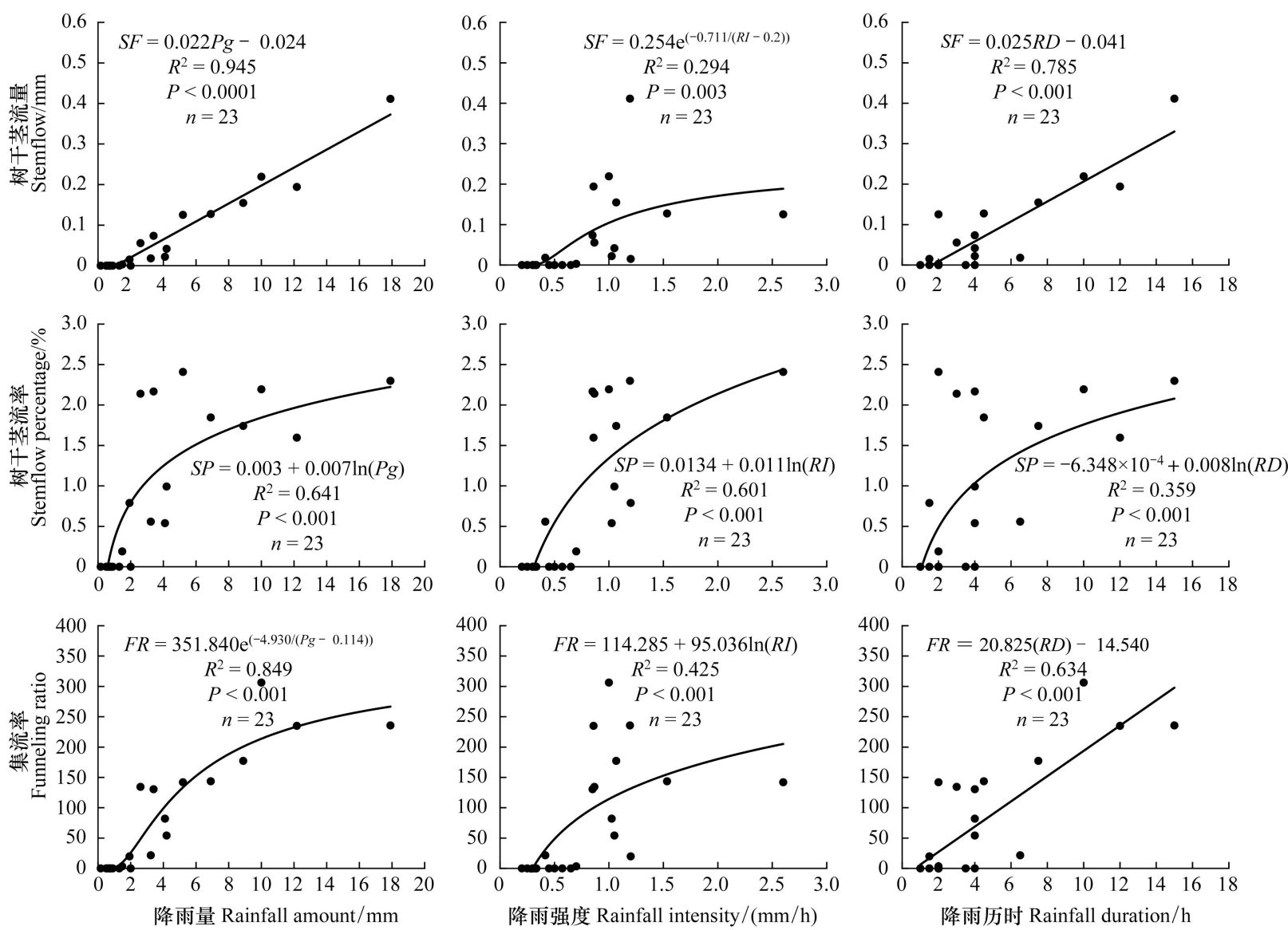

图 6 树干茎流量、树干茎流率及集流率与降雨特征之间的回归关系

Fig.6 The correlation between stemflow, stemflow percentage, funneling ratio and rainfall regimes

$S F$ : 树干茎流量 Stemflow; SP: 树干茎流率 Stemflow percentage; FR: 集流率 Funneling ratio

降雨特征在冠层截留损失形成的过程中发挥重要作用,回归分析和曲线拟合的结果表明,泡泡刺灌丛的 冠层截留损失量与降雨特征之间呈对数函数关系 $(P<0.01)$ (图 7)。当降雨量 $<4 \mathrm{~mm}$ 、降雨强度 $<1 \mathrm{~mm} / \mathrm{h}$ 、降 雨历时 $<4 \mathrm{~h}$ 时, 冠层截留损失的增加速率较快, 随后冠层截留损失的增加速率放缓, 最终趋于一定值 (约为 $1 \mathrm{~mm})$ 。该现象可能与泡泡刺灌丛的冠层持水能力有关。冠层截留损失率随降雨量和降雨历时的增加呈现 线性下降趋势 $(P<0.05)$, 与降雨强度之间无显著相关性, 表明短历时的小降雨事件比长历时的大降雨事件更 易造成冠层截留损失。

冠层结构特征对冠层截留损失的影响同样不可忽视,但单株泡泡刺的冠层截留损失量与冠层结构特征的 相关性分析表明,泡泡刺的冠层截留损失量与树干倾角、PAI、基径、株高和冠层厚度之间均无显著的相关性 (表 3)。

表 3 单株泡泡刺的冠层截留损失量与冠层结构特征的相关分析

Table 3 Correlation analysis of interception loss with canopy morphological characteristics for single Nitraria sphaerocarpa

\begin{tabular}{lccccc}
\hline & $\begin{array}{c}\text { 树干倾角 } \\
\text { Stem } \\
\text { orientation } /\left({ }^{\circ}\right)\end{array}$ & $\begin{array}{c}\text { PAI } \\
\text { Plant area } \\
\text { index } /\left(\mathrm{m}^{2} / \mathrm{m}^{2}\right)\end{array}$ & $\begin{array}{c}\text { 基径 } \\
\text { Stem } \\
\text { diameter } / \mathrm{cm}\end{array}$ & $\begin{array}{c}\text { 株高 } \\
\text { Shrub } \\
\text { height } / \mathrm{cm}\end{array}$ & $\begin{array}{c}\text { 冠层厚度 } \\
\text { Canopy } \\
\text { thickness } / \mathrm{cm}\end{array}$ \\
\hline 冠层截留损失量 Interception loss $/ \mathrm{mm}$ & 0.11 & 0.31 & -0.44 & 0.51 & 0.50 \\
\hline
\end{tabular}

* 表示在 0.05 级别 (双尾), 相关性显著; $* *$ 表示在 0.01 级别 (双尾), 相关性显著 

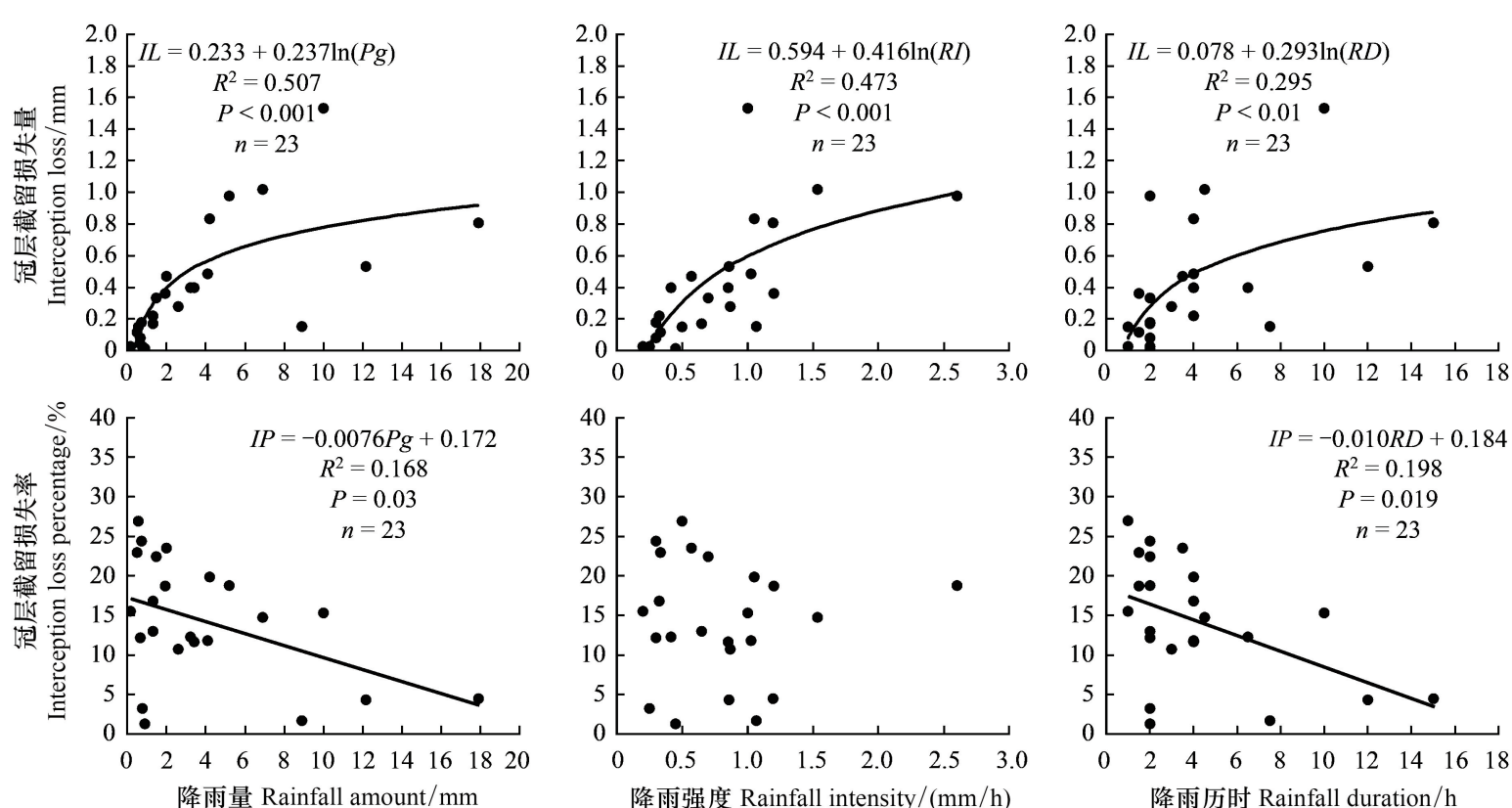

降雨强度 Rainfall intensity $/(\mathrm{mm} / \mathrm{h})$

降雨历时 Rainfall duration $/ \mathrm{h}$

图 7 冠层截留损失量、冠层截留损失率与降雨特征之间的回归关系

Fig.7 The correlation between canopy interception loss, canopy interception loss percentage and rainfall regimes $I L$ : 冠层截留损失量 Interception loss; IP: 冠层截留损失率 Interception loss percentage

2.5 冠层降雨再分配与其他气象因子的关系

为进一步探索其他气象因子对冠层降雨再分配过程的影响,选取平均风速、平均净辐射、冠层表面温度、 平均大气温度和平均水汽压等 6 个要素反映气象特征, 运用 Pearson 相关分析检验各气象因子与冠层降雨再 分配要素的相关性 (表 4)。结果表明,穿透雨量和冠层截留损失量与各气象因子之间无显著相关性; 而穿透 率和冠层截留损失率与冠层表面温度、平均大气温度及平均水汽压之间具有显著的相关性 $(P<0.05)$, 分别呈 负相关和正相关关系, 可能是由于当冠层表面温度、平均大气温度、平均水汽压较高时,冠层表面的蒸发潜力 较大, 促进了冠层截留雨水向冠层截留损失转化,进而导致冠层截留损失率的增加和穿透率的减少; 树干茎流 量和树干茎流率与平均大气湿度呈现显著正相关关系 $(P<0.05)$, 可能是由于随大气湿度的增加, 大气饱和差 减小,在一定程度上抑制了蒸发的产生,促进了冠层截留雨水向树干茎流转化。

表 4 冠层降雨再分配要素与气象因子的相关性分析

Table 4 Correlation analysis of rainfall partitioning with meteorological factors

\begin{tabular}{|c|c|c|c|c|c|c|}
\hline $\begin{array}{l}\text { 冠层降雨再分配要素 } \\
\text { Rainfall partitioning }\end{array}$ & $\begin{array}{c}\text { 平均风速 } \\
\text { Mean wind } \\
\text { speed/ } \\
(\mathrm{m} / \mathrm{s})\end{array}$ & $\begin{array}{c}\text { 平均净辐射 } \\
\text { Mean net } \\
\text { radiation/ } \\
\left(\mathrm{w} / \mathrm{m}^{2}\right)\end{array}$ & $\begin{array}{l}\text { 冠层表面温度 } \\
\text { Canopy surface } \\
\text { temperature } /{ }^{\circ} \mathrm{C}\end{array}$ & $\begin{array}{c}\text { 平均大气温度 } \\
\text { Mean atmospheric } \\
\text { temperature } /{ }^{\circ} \mathrm{C}\end{array}$ & $\begin{array}{c}\text { 平均大气湿度 } \\
\text { Mean atmospheric } \\
\text { humidity/\% }\end{array}$ & $\begin{array}{l}\text { 平均水汽压 } \\
\text { Mean vapor } \\
\text { pressure/hPa }\end{array}$ \\
\hline 穿透雨量 Throughfall/mm & -0.25 & -0.12 & -0.25 & -0.26 & 0.41 & 0.010 \\
\hline $\begin{array}{l}\text { 穿透率 } \\
\text { Throughfall percentage/\% }\end{array}$ & 0.017 & -0.34 & $-0.64^{* *}$ & $-0.61^{* *}$ & 0.21 & $-0.49^{*}$ \\
\hline 树干茎流量 Stemflow/mm & -0.21 & -0.18 & -0.19 & -0.21 & $0.45^{*}$ & 0.10 \\
\hline $\begin{array}{l}\text { 树干茎流率 } \\
\text { Stemflow percentage/\% }\end{array}$ & 0.0051 & -0.18 & -0.074 & -0.11 & $0.45^{*}$ & 0.23 \\
\hline $\begin{array}{l}\text { 冠层截留损失量 } \\
\text { Interception loss/mm }\end{array}$ & -0.060 & 0.15 & 0.19 & 0.16 & 0.27 & 0.38 \\
\hline $\begin{array}{l}\text { 冠层截留损失率 } \\
\text { Interception loss percentage/\% }\end{array}$ & -0.019 & 0.35 & $0.62^{* *}$ & $0.60^{* * *}$ & -0.26 & $0.45^{*}$ \\
\hline
\end{tabular}

* 表示在 0.05 级别 (双尾), 相关性显著; **表示在 0.01 级别 (双尾), 相关性显著 


\section{3 讨论}

在干旱区, 水分是限制植被生长发育的关键因素, 其数量及时空分布决定着植被的发育过程和生长模 式 ${ }^{[1,11]}$ 。降雨作为该地区的主要补给水源, 植被冠层对于降雨的再分配特征将直接影响冠层下可供植被利 用的有效水分 ${ }^{[47]}$ 。因此,量化泡泡刺灌丛覆盖下实际进人土壤的有效降雨量及其空间分布规律, 对深人理解 绿洲-荒漠过渡带植被对降水再分配过程的调节及其在局地水文循环中的作用具有重要科学意义。

3.1 泡泡刺灌丛的降雨再分配特征

试验期间泡泡刺灌丛的穿透雨量、树干茎流量和冠层截留损失量分别为 $79.89 \mathrm{~mm} 、 1.46 \mathrm{~mm} 、 9.54 \mathrm{~mm}$, 分 别占总降雨量 $87.89 \% 、 1.61 \% 、 10.50 \%$ (具体见图 8)。与阿根廷中部的极叉开拉瑞阿 (Larrea divaricata)

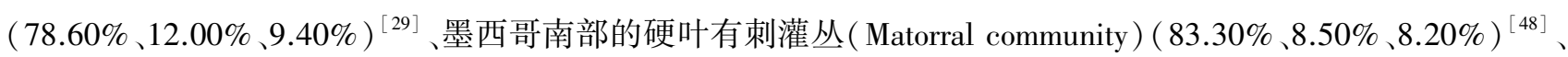
科尔沁沙地的黄柳 $(82.78 、 2.19 \% 、 15.03 \%)^{[49]}$ 及沙坡头地区油蒿 $(74.83 \% 、 2.89 \% 、 22.28 \%)^{[2]}$ 的降雨再分配 特征类似,但相对来说, 泡泡刺灌丛的平均穿透率较高, 平均树干茎流率和冠层截留损失率较低,可能与泡泡 刺灌丛特殊的植被形态特征有关。泡泡刺灌丛的树枝较细、树干表面粗糙且树枝大多呈现匍匐状贴近地表， 所以其树干茎流量较少 ${ }^{[17,50-51]}$ 。同时,含有蜡质层的卵形叶片也不易于截留降雨 ${ }^{[18,52]}$, 易促进雨水以穿透雨 的形式滴落。此外,与其他植被相比,泡泡刺灌丛较为低矮, 冠层体积和厚度较小, 冠层持水能力较弱,因此, 降雨在冠层内的停滞时间短, 冠层截留损失和树干茎流相对较小, 大部分雨水以穿透雨的形式到达地面。

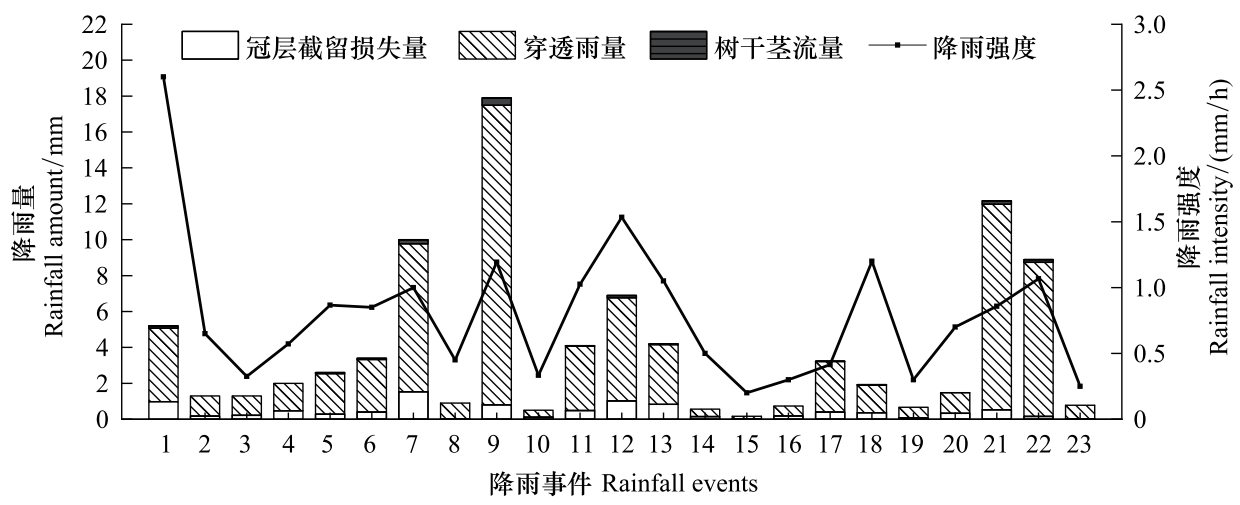

图 8 实验期间穿透雨量、树干茎流量、冠层截留损失量和降雨强度的变化

Fig.8 Variation of throughfall, stemflow, interception loss and rainfall intensity during the experiment

\section{2 泡泡刺灌丛覆盖条件下的有效降雨量}

冠层下净降雨量的多塞及其空间分布决定着冠层下土壤水分的空间分布格局 ${ }^{[47]}$, 进而对植被的生长发 育产生重要影响 ${ }^{[29,50-51]}$ 。因此, 净降雨量也被称为冠层下的有效降雨量, 反映了植被对雨水的利用效率 ${ }^{[53]}$ 。 实验期间泡泡刺灌丛共产生净降雨量 $81.36 \mathrm{~mm}$, 约占总降雨量的 $89.50 \%$, 其中穿透雨约占净降雨量的 $98.20 \%$,树干茎流约占净降雨量的 $1.80 \%$ 。

树干茎流虽然数量较少, 却能以点源的形式将雨水汇集并输送至深层土壤中供给植物根部使用 ${ }^{[11,17,29]}$, 通常使用集流率来反映树干茎流的聚集效应 ${ }^{[15]}$ 。统计发现,泡泡刺灌丛的平均集流率约为 $(129.66 \pm 93.01)$, 与科尔沈沙地的小叶锦鸡儿(100.1)、黄柳 (106.2) ${ }^{[50]}$ 及臬兰地区的柠条 (153.5 $)^{[17]}$ 类似,高于毛乌素沙地的 籽蒿(41.5)、沙柳 (64.9) ${ }^{[54]}$ 及沙坡头地区的油蒿 (26) ${ }^{[18]}$, 表明泡泡刺灌丛的树干茎流对根际区土壤水分具 有明显的补给作用, 同时,也证明除树干外,泡泡刺灌丛的叶片及枝条有效地促进了树干茎流的形成。此外, 回归分析发现,存在一个雨量 (约为 $6 \mathrm{~mm}$ ) 和雨强 (约为 $0.8 \mathrm{~mm} / \mathrm{h}$ ) 的阈值,在此阈值之后,泡泡刺灌丛的集流 率随雨量、雨强的增加速率明显减缓, 意味着较大的雨量和雨强可能会降低树干茎流的集流效率, 这与 Carlyle - Moses 等 ${ }^{[55]}$ 提出的集流率可能受降雨量阈值的限制相符。 
穿透雨是有效降雨量的主要组分, 对冠层下表层土壤水分的空间分布产生不可忽视的影响 ${ }^{[11]}$ 。研究发 现穿透雨的空间分布存在显著的空间异质性,主要表现为多个“雨极”和“旱区”镶嵌分布的模式,与毛素沙地 南缘散生中间锦鸡儿 ${ }^{[56]}$ 和地中海地区松树 ${ }^{[12]}$ 的穿透雨空间分布格局类似。该现象在低雨强、短历时的小降 雨事件中表现最为显著,随雨量和雨强的增加而减弱, 可能是由于高雨强、长历时的大降雨事件更易促进冠层 饱和,加速截留雨水迸溅导致。在降雨特征相同的情况下,PAI 的空间异质性成为影响穿透雨空间分布格局 的关键因素, PAI 越大, 雨水越易被冠层截留, 不易产生穿透雨。此外, 穿透雨的空间异质性也意味着我们在 实验中应尽可能多的增加雨量筒的数量以减小实验误差。

3.3 泡泡刺灌丛的冠层截留损失

冠层截留损失作为降雨再分配过程中的净损失项, 其大小直接影响冠层下有效降雨量的多少 ${ }^{[12]}$ 。除了 受气象条件和降雨特征的影响外, 冠层持水能力也是影响冠层截留损失的重要因素 ${ }^{[57-58]}$, 通常将冠层持水能 力定义为冠层表面完全湿润所需要的最小降雨量 ${ }^{[59]}$ 。实验中发现泡泡刺灌丛的冠层持水能力可能会影响冠 层截留损失随降雨特征的变化趋势, 在低雨强、短历时的小降雨事件中, 泡泡刺灌丛具有较强的截留吸附能 力,截留雨水大多以冠层截留蒸发的形式消耗,此时冠层截留损失的增加速率较快, 但随着雨量、雨强和历时 的增加, 当冠层处于饱和或过饱和状态时, 超出冠层持水能力的截留雨水可能会转化为穿透雨和树干茎流, 进 而导致冠层截留损失的增加速率减缓并趋于稳定。Jian 等 ${ }^{[28,60-61]}$ 在对我国干旱区稀疏植被的冠层截留损失 进行观测时也发现类似现象。根据 Wallence 等 ${ }^{[62]}$ 提出的间接方法推算泡泡刺灌丛的冠层持水能力约为 $0.42 \mathrm{~mm}$, 显著低于黄土高原地区的刺槐 $(1.34 \mathrm{~mm})$ 和油松 $(1.43 \mathrm{~mm})^{[19]}$ 、青海地区的金露梅 $(0.55 \mathrm{~mm})^{[34]}$ 、

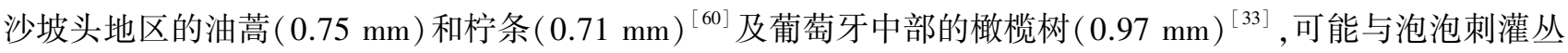
低矮的冠层、较小的冠层体积、匍匐状的枝条及含有蜡质层的叶片有关, 这也是导致泡泡刺灌丛冠层截留损失 率较低的关键原因之一。

与其他稀疏植被相比,泡泡刺灌丛具有较高的穿透率、树干集流率及较低的冠层截留损失率, 更有利于促 进大气降雨量转化为冠层下的有效雨量, 减少冠层截留损失造成的水分净损失, 对干旱区局地水文过程和水 文循环产生不可忽视的影响。除气象因素外,植被形态结构特征也在泡泡刺灌丛降雨再分配的过程中发挥重 要作用,如退化的枝条、较小且含有蜡质层的叶片等有效地促进了冠层下水分的补给、提高了对于雨水的利用 效率。

\section{4 结论}

基于对河西走廊中段绿洲-荒漠过渡带的泡泡刺灌丛开展长期冠层降雨再分配的定位观测实验,通过对 其降雨再分配特征及影响因素进行分析,得到以下结论:

(1) 实验期间共观测到有效降雨事件 23 次, 总降雨量为 $90.9 \mathrm{~mm}$, 泡泡刺灌丛的平均穿透率、树干茎流率 和冠层截留损失率分别为 $87.89 \% 、 1.61 \%$ 和 $10.50 \%$ 。穿透雨和树干茎流产生的阈值分别为 $0.2 \mathrm{~mm}$ 和 1.5 $\mathrm{mm}$, 冠层持水能力约为 $0.42 \mathrm{~mm}$ 。

(2) 降雨特征是影响泡泡刺灌丛冠层降雨再分配过程的关键气象要素, 回归分析发现, 穿透雨量与降雨 量、降雨强度、降雨历时之间分别呈现线性、幂函数和线性函数关系 $(P<0.01)$, 穿透率与降雨历时之间用线性 函数的拟合效果较好 $(P=0.04)$; 树干茎流量与降雨量、降雨强度、降雨历时之间分别呈现线性、指数和线性函 数关系 $(P<0.01)$, 树干茎流率、冠层截留损失量与降雨特征之间分别呈现对数函数关系 $(P<0.01)$; 冠层截留 损失率与降雨量、降雨历时之间用线性函数的拟合效果较好 $(P<0.05)$ 。其他气象要素 ( 如平均大气温湿度、 水汽压、冠层表面温度等) 也在降雨再分配的过程中发挥不可忽视的作用。

(3) 植被形态结构特征是影响冠层降雨再分配过程的另一重要因素,相关分析表明,穿透雨与 PAI 和株 高之间呈现显著的负相关关系 $(P<0.0001), \mathrm{PAI}$ 的空间异质性可能是影响穿透雨空间分布异质性的主要因 素; 树干茎流与树干倾角之间呈现显著的正相关关系 $(P<0.01)$, 随树干倾角的增加而增加。与其他干旱区稀 
疏植被相比,泡泡刺灌丛的穿透率和树干集流率较大, 冠层截留损失率较小, 主要与泡泡刺灌丛特殊的植被形 态特征有关。

\section{参考文献 (References) :}

[ 1 ] Fathizadeh O, Hosseini S M, Zimmermann A, Keim R F, Boloorani A D. Estimating linkages between forest structural variables and rainfall interception parameters in semi-arid deciduous oak forest stands. Science of the Total Environment, 2017, 601-602: 1824- 1837.

[ 2 ] Zhang Y F, Wang X P, Hu R, Pan Y X, Paradeloc M. Rainfall partitioning into throughfall, stemflow and interception loss by two xerophytic shrubs within a rain-fed re-vegetated desert ecosystem, northwestern China. Journal of Hydrology, 2015, 527: 1084- 1095.

[ 3 ] Dingman S L. Physical Hydrology. 3rd ed. Long Grove: Waveland Press, 2015: 285.

[ 4 ] Garcia-Estringana P, Alonso-Blázquez N, Alegre J. Water storage capacity, stemflow and water funneling in Mediterranean shrubs. Journal of Hydrology, 2010, 389(3/4) : 363-372.

[ 5 ] Zheng C L, Jia L. Global canopy rainfall interception loss derived from satellite earth observations. Ecohydrology, 2020, 13(2): e2186.

[ 6 ] David T S, Gash J H C, Valente F, Pereira J S, Ferreira M I, David J S. Rainfall interception by an isolated evergreen oak tree in a Mediterranean savannah. Hydrological Processes, 2006, 20(13) : 2713-2726.

[ 7 ] Dunkerley D. Measuring interception loss and canopy storage in dryland vegetation: a brief review and evaluation of available research strategies. Hydrological Processes, 2000, 14(4): 669-678.

[ 8 ] Yang X G, Chen L, Wang L, Wang X, Gu J L, Qu W J, Song N P. Dynamic rainfall-partitioning relationships among throughfall, stemflow, and interception loss by Caragana intermedia. Journal of Hydrology, 2019, 574: 980-989.

[ 9 ] 王新平, 康尔泗, 张景光, 李新荣. 荒漠地区主要固沙灌木的降水截留特征. 冰川冻土, 2004, 26( 1) : 89-94.

[10］徐先英, 严平, 郭树江, 柴成武. 干旱荒漠区绿洲边缘典型固沙灌木的降水截留特征. 中国沙漠, 2013, 33(1) : 141- 145.

[11] Llorens P, Domingo F. Rainfall partitioning by vegetation under Mediterranean conditions. A review of studies in Europe. Journal of Hydrology, $2007,335(1 / 2): 37-54$.

[12] Shachnovich Y, Berliner P R, Bar P. Rainfall interception and spatial distribution of throughfall in a pine forest planted in an arid zone. Journal of Hydrology, 2008, 349(1/2): 168- 177.

[13] Levia Jr D F, Frost E E. A review and evaluation of stemflow literature in the hydrologic and biogeochemical cycles of forested and agricultural ecosystems. Journal of Hydrology, 2003, 274(1/4): 1-29.

[14］杨志鹏，李小雁，伊万娟. 荒漠灌木树干茎流及其生态水文效应研究进展. 中国沙漠, 2010, 30(2) : 303-311.

[15] Herwitz S R. Infiltration-excess caused by stemflow in a cyclone-prone tropical rainforest. Earth Surface Processes and Landforms, 1986, 11(4) : 401-412.

[16] Levia Jr D F, Herwitz S R. Physical properties of water in relation to stemflow leachate dynamics: implications for nutrient cycling. Canadian Journal of Forest Research, 2000, 30(4): 662-666.

[17] Li X Y, Liu L Y, Gao S Y, Ma Y J, Yang Z P. Stemflow in three shrubs and its effect on soil water enhancement in semiarid loess region of China. Agricultural and Forest Meteorology, 2008, 148(10): 1501- 1507.

[18] Zhang Y F, Wang X P, Hu R, Pan Y X, Hao Z. Stemflow in two xerophytic shrubs and its significance to soil water and nutrient enrichment. Ecological Research, 2013, 28(4): 567-579.

[19] Ma C K, Li X D, Luo Y, Shao M A, Jia X X. The modelling of rainfall interception in growing and dormant seasons for a pine plantation and a black locust plantation in semi-arid Northwest China. Journal of Hydrology, 2019, 577: 123849.

[20］王正宁，王新平. 荒漠灌丛树干茎流及其人渗、再分配特征. 中国沙漠，2010，30(5)：1108-1113.

[21］高光耀, 傅伯杰, 吕一河, 刘宇, 王帅, 周继. 干旱半干旱区坡面覆被格局的水土流失效应研究进展. 生态学报, 2013, 33(1)：12-22.

[22] 胡广录, 赵文智. 干旱半干旱区植被生态需水量计算方法评述. 生态学报, 2008, 28(12): 6282-6291.

[23] 李小雁. 干旱地区土壤-植被-水文耦合、响应与适应机制. 中国科学: 地球科学, 2011, 41(12): 1721-1730.

[24] Zhang Y F, Wang X P, Hu R, Pan Y X. Throughfall and its spatial variability beneath xerophytic shrub canopies within water-limited arid desert ecosystems. Journal of Hydrology, 2016, 539: 406-416.

[25] Barbier S, Balandier P, Gosselin F. Influence of several tree traits on rainfall partitioning in temperate and boreal forests: a review. Annals of Forest Science, 2009, 66(6): 602.

[26] Buttle J M, Toye H J, Greenwood W J, Bialkowski R. Stemflow and soil water recharge during rainfall in a red pine chronosequence on the Oak Ridges Moraine, southern Ontario, Canada. Journal of Hydrology, 2014, 517: 777-790.

[27] Klingaman N P, Levia D F, Frost E E. A comparison of three canopy interception models for a leafless mixed deciduous forest stand in the eastern United States. Journal of Hydrometeorology, 2007, 8(4) : 825-836.

[28] Jian S Q, Hu C H, Zhang G D, Zhang J P. Study on the throughfall, stemflow, and interception of two shrubs in the semiarid Loess region of China. Agricultural and Forest Meteorology, 2019, 279: 107713.

[29] Magliano P N, Whitworth-Hulse J I, Florio E L, Aguirre E C, Blanco L J. Interception loss, throughfall and stemflow by Larrea divaricata: the role of rainfall characteristics and plant morphological attributes. Ecological Research, 2019, 34(6) : 753-764.

[30] Zhang Z S, Zhao Y, Li X R, Huang L, Tan H J. Gross rainfall amount and maximum rainfall intensity in 60-minute influence on interception loss of shrubs: a 10-year observation in the Tengger Desert. Scientific Reports, 2016, 6: 26030.

[31] Owens M K, Lyons R K, Alejandro C L. Rainfall partitioning within semiarid juniper communities: effects of event size and canopy cover. 
Hydrological Processes, 2006, 20(15): 3179-3189.

[32] Ma C K, Luo Y, Shao M A. Comparative modeling of the effect of thinning on canopy interception loss in a semiarid black locust (Robinia pseudoacacia) plantation in Northwest China. Journal of Hydrology, 2020, 590: 125234.

[33] Valente F, Gash J H, Nóbrega C, David J S, Pereira F L. Modelling rainfall interception by an olive-grove/pasture system with a sparse tree canopy. Journal of Hydrology, 2020, 581: 124417.

[34] Zhang S Y, Li X Y, Jiang Z Y, Li D Q, Lin H. Modelling of rainfall partitioning by a deciduous shrub using a variable parameters Gash model. Ecohydrology, 2018, 11(7): e2011.

[35］魏乐, 宋乃平, 方楷. 宁夏荒漠草原植物群落的空间异质性. 草业科学, 2014, 31(5): 826-832.

[36] Crockford R H, Richardson D P. Partitioning of rainfall into throughfall, stemflow and interception: effect of forest type, ground cover and climate. Hydrological Processes, 2000, 14(16/17): 2903-2920.

[37] 冯金朝, 刘新民. 干旱环境与植物的水分关系. 北京: 中国环境科学出版社, 1998: 8-8.

[38] 赵鹏, 徐先英, 纪永福, 李亚, 安富博, 张慧文. 民勤绿洲边缘不同演替阶段白刺灌丛水分利用动态. 干旱区资源与环境, 2019, 33(9)： 168-175.

[39］周海, 赵文智, 何志斌. 两种荒漠生境条件下泡泡刺水分来源及其对降水的响应. 应用生态学报, 2017, 28(7)：2083-2092.

[40] Ji X B, Zhao W Z, Kang E S, Jin B W, Xu S Q. Transpiration from three dominant shrub species in a desert-oasis ecotone of arid regions of Northwestern China. Hydrological Processes, 2016, 30(25): 4841-4854.

[41] 徐世琴. 绿洲-荒漠交错带典型固沙植物水分传输过程研究 [D]. 北京: 中国科学院大学, 2016.

[42] Chen J M, Black T A, Adams R S. Evaluation of hemispherical photography for determining plant area index and geometry of a forest stand. Agricultural and forest meteorology, 1991, 56(1/2): 129-143.

[43] Smolander H, Stenberg P. Response of LAI-2000 estimates to changes in plant surface area index in a Scots pine stand. Tree physiology, 1996, 16 (3) : 345-349.

[44] Holst T, Hauser S, Kirchgäßner A, Matzarakis A, Mayer H, Schindler D. Measuring and modelling plant area index in beech stands. International Journal of Biometeorology, 2004, 48(4) : 192-201.

[45] Sanusi R, Johnstone D, May P, Livesley S J. Microclimate benefits that different street tree species provide to sidewalk pedestrians relate to differences in Plant Area Index. Landscape and Urban Planning, 2017, 157: 502-511.

[46] 杨茂瑞. 亚热带杉木、马尾松人工林的林内降雨、林冠截留和树干茎流. 林业科学研究, 1992, 5(2): 158-162.

[47] Martinez-Meza E, Whitford W G. Stemflow, throughfall and channelization of stemflow by roots in three Chihuahuan desert shrubs. Journal of Arid Environments, 1996, 32(3): 271-287.

[48] Carlyle-Moses D E. Throughfall, stemflow, and canopy interception loss fluxes in a semi-arid Sierra Madre Oriental matorral community. Journal of Arid Environments, 2004, 58(2): 181-202.

[49] 岳祥飞, 崔建垣, 张铜会, 王少昆, 连杰, 王新源, 云建英. 科尔沈沙地黄柳灌丛降雨截留与再分配特征. 草业学报, 2013, 22(6)： 46-52.

[50] Shou W K, Musa A, Liu Z M, Qian J Q, Niu C Y, Guo Y H. Rainfall partitioning characteristics of three typical sand-fixing shrubs in Horqin Sand Land, north-eastern China. Hydrology Research, 2017, 48(2) : 571-583.

[51] Magliano P N, Whitworth-Hulse J I, Baldi G. Interception, throughfall and stemflow partition in drylands: Global synthesis and meta-analysis. Journal of Hydrology, 2019, 568: 638-645.

[52] Wang X P, Zhang Y F, Hu R, Pan Y X, Berndtsson R. Canopy storage capacity of xerophytic shrubs in Northwestern China. Journal of Hydrology, 2012, 454-455: 152-159.

[53] 田娜, 古君龙, 杨新国, 王否, 王兴, 陈林, 宋乃平. 中间锦鸡儿冠层降雨再分配特征. 干旱区研究, 2019, 36(4) : 854-862.

[54] 杨志鹏, 李小雁, 刘连友, 武建军, 哈斯, 孙永亮. 毛乌素沙地固沙灌木树干茎流特征. 科学通报, 2008, 53(8) : 939-945.

[55] Carlyle-Moses D E, Price A G. Growing-season stemflow production within a deciduous forest of southern Ontario. Hydrological Process, 2006, 20 (17) : 3651-3663.

[56] 杨新国, 古君龙, 王兴, 陈林, 王否, 宋乃平, 曲文杰. 荒漠草原中间锦鸡儿( Caragana intermedia) 冠层穿透雨的发生与分布特征. 干旱 区研究, 2019, 36(1) : 131-138.

[57] David J S, Valente F, Gash J H. Evaporation of intercepted rainfall: Part 4. Hydrometeorology//Anderson M G, ed. Encyclopedia of Hydrological Sciences. New Jersey: John Wiley \& Sons, Ltd, 2005: 627-634.

[58］李新荣, 张志山, 刘玉冰, 李小军, 杨吴天. 中国沙区生态重建与恢复的生态水文学基础. 北京: 科学出版社, 2016: 80-80.

[59] Rutter A J, Kershaw K A, Robins P C, Morton A J. A predictive model of rainfall interception in forests, 1. Derivation of the model from observations in a plantation of Corsican pine. Agricultural Meteorology, 1971-1972, 9: 367-384.

[60] Wang X P, Li X R, Zhang J G, Zhang Z S, Berndtsson R. Measurement of rainfall interception by xerophytic shrubs in re-vegetated sand dunes. Hydrological Sciences Journal, 2005, 50(5): 910.

[61] 田娜, 古君龙, 杨新国, 王否, 杨东东, 苗翻, 孟明. 荒漠草原中间锦鸡儿冠层截留特征. 生态学报, 2019, 39(14): $5279-5287$.

[62] Wallace J, McJannet D. Modelling interception in coastal and montane rainforests in northern Queensland, Australia. Journal of Hydrology, 2008, $348(3 / 4): 480-495$. 